\title{
PRÁTICAS ORGANIZACIONAIS DO MOVIMIENTO DE TRABAJADORES DESOCUPADOS DE LA MATANZA À LUZ DO PENSAMENTO DE PAULO FREIRE
}

\author{
ORGANIZATIONAL PRACTICES IN MOVIMIENTO DE TRABAJADORES DESOCUPADOS \\ DE LA MATANZA UNDER PAULO FREIRE'S PERSPECTIVE
}

Recebido em 24.07.2018. Aprovado em 17.08.2018

Avaliado pelo sistema double blind review

DOI: http://dx.doi.org/10.12712/rpca.v12i3.12576

\author{
Joysi Moraes \\ jmoraes@id.uff.br \\ Universidade Federal Fluminense (UFF), Niterói/RJ, BRASIL \\ https://orcid.org/0000-0003-0133-1111
}

\section{Maria Ceci Araujo Misoczky}

maria.ceci@ufrgs.br

Universidade Federal do Rio Grande do Sul (UFRGS), Porto Alegre/RS, BRASIL

https:/ / orcid.org/0000-0003-2020-5882

\section{Resumo}

A concepção de Paulo Freire acerca da 'pedagogia libertadora' pressupõe como inseparáveis a prática organizativa e o processo de ensino-aprendizagem. $\mathrm{Na}$ perspectiva freireana, a prática pedagógica acontece como um exercício de auto-organização entre aqueles que a utilizam e somente é consolidada durante o próprio processo de auto-organização dos sujeitos. Nestes termos, analisamos, sob a perspectiva do pensamento freireano, as práticas organizacionais de um movimento social da América Latina, o Movimiento de Trabajadores Desocupados de La Matanza (MTD La Matanza na Argentina.

Palavras-chave: Paulo Freire. Práticas Organizacionais. 'Pedagogia Libertadora'.

\begin{abstract}
Paulo Freire's conception of 'liberating pedagogy' presupposes as inseparable the organizational practice and the teaching-learning process. In the Freirean perspective, the pedagogical practice happens as an exercise of self-organization between those who use it. And this pedagogical practice is only consolidated during the process of self-organization of the subjects. In these terms, we analyze, under the Freirean perspective, the organizational practices in a social movement in Latin America, the Movimiento de Trabajadores Desocupados de La Matanza (MTD La Matanza na Argentina in Argentina.
\end{abstract}

Keywords: Paulo Freire. Organizational practices. 'Liberating Pedagogy'. 


\section{Introdução}

A abordagem central deste artigo diz respeito à "organização como meio e aprendizagem para a práxis emancipadora". Desse modo, no texto é apresentada a concepção teóricometodológica de Paulo Freire acerca de uma 'pedagogia libertadora' que pressupõe como inseparáveis a prática organizativa e o processo de ensino-aprendizagem. Isto porque a prática pedagógica freireana, por uma questão de coerência interna, se dá, antes, como um exercício de auto-organização entre aqueles que a utilizam e, somente é consolidada durante o próprio processo de auto-organização dos sujeitos, ou seja, no processo autogestionário e não no processo heterogestionário. Caso contrário, o que se imporia seria, novamente, segundo a lógica freireano, a pedagogia tradicional, ou seja, aquela baseada em relações hierárquicas no processo de ensino-aprendizagem, antecedida, portanto, por práticas organizativas verticalizadas.

A escolha da perspectiva freireana ainda se deve ao fato que esta traz consigo fundamentos para a compreensão dos processos organizacionais a partir de uma racionalidade substantiva, que não tem como base de solução dos problemas meramente o cálculo meios-fins. Um tipo de racionalidade que existe como uma manifestação da capacidade inerente do homem de agir racionalmente com base em valores, dado que, para Paulo Freire, somente a ação orientada pela racionalidade substantiva transforma a ação em si e introduz a possibilidade de uma organização ou de práticas organizacionais dialógicas.

Para corroborar com o pensamento freireano, e ainda tornar visíveis algumas práticas organizacionais de movimentos sociais na América Latina, é apresentado ao longo do artigo o processo organizativo de formação do Movimiento de Trabajadores Desocupados de La Matanza. Um movimento social argentino que começou a se organizar em 1995 e cuja origem tem lugar no Município de La Matanza, uma das regiões mais pobres do país, com cerca de dois milhões de habitantes.

A pesquisa realizada se caracteriza como um estudo de caso que só pode ser compreendido como um fenômeno que ocorre dentro de um contexto intrinsecamente delimitado e inserido em algum contexto da vida real. Foram utilizados os recursos da observação participante, da entrevista semiestruturada e da análise documental. A observação participante "é realizada no transcurso da vida cotidiana de pessoas ou de grupos, a fim de conhecer, a partir dessa posição interna, eventos, fenômenos ou circunstâncias aos quais não se poderia ter acesso de uma posição externa não participante (MONTERO, 2006, p. 205). Assim, quando "se diz que o observador participante se coloca no meio da vida cotidiana das pessoas as quais observa, se indica a proximidade, o que exclui esta técnica do que se tem chamado de epistemologia da distância" (MONTERO, 2006, p. 206). Angrosino e Pérez (2000) salientam que quando um pesquisador também participa ativamente das atividades do grupo que está investigando, há maiores possibilidades de compreender as relações de poder que se passam nesse grupo, pois pode perceber comportamentos que só fazem sentido naquela situação específica.

Para a construção do artigo, primeiro são realizadas considerações acerca de algumas palavras utilizadas por Paulo Freire para que se possa ter uma compreensão mais assertiva do texto freireano e, principalmente, para evitar equívocos semânticos a respeito do que trata o autor. A seguir, é apresentado o contexto no qual nasceram os Movimentos de Trabalhadores Desocupados (MTDs) na Argentina, entre eles, o MTD de La Matanza. O tópico seguinte trata do surgimento, configuração e das práticas organizacionais que vêm sendo experimentadas por esse MTD. As falas dos entrevistados (em itálico) estão intercalando o texto nesse item. Concomitantemente é realizada a compreensão e análise de sua história a partir do olhar freireano.

\section{Primeiras palavras acerca de Paulo Freire}

Para uma compreensão mais assertiva do texto freireano são necessários alguns esclarecimentos. Inúmeras vezes, Paulo Freire utiliza as palavras 'revolução' e 'radical' nos seus textos. Para um desavisado imbuído de senso comum, tais palavras poderiam soar como a incitação a um golpe de Estado, exemplo do próprio Paulo Freire, e ao recurso à violência. Quando, de fato, o autor, em suas principais obras esclarece do que trata: do diálogo, do direito de pronunciar a palavra, de ser consciente. Em nenhum momento, em seus textos, Paulo Freire, incita tais processos. Ao contrário, primeiro porque Freire (2005b, p. 205) entende que, "se para a elite dominadora, a organização é a de si mesma; para a liderança revolucionária, a organização é a dela (elite dominadora) com as massas populares". Isto é, para esta última não há segregação, ou seria mera repetição de procedimentos de dominação, pois somente mudariam os dominadores.

"No primeiro caso, organizando-se, a elite dominadora estrutura cada vez mais o seu poder com que melhor domina e coisifica; no segundo, a organização só corresponde à sua natureza e a seu objetivo se é, em si, prática de liberdade" (FREIRE, 2005b, p. 205). Como assinala o autor, "dos 
golpes, seria ingenuidade esperar que estabelecessem algum tipo de diálogo", quando esse, na verdade, "é uma exigência radical”, é uma revolução exatamente por isso, porque é um processo dialógico, ainda não tentado pelos seres humanos no afã mesmo da transformação da realidade; "dos golpes, o que se pode esperar é o engodo para legitimar-se ou a força que reprime", não a ação dialógica (FREIRE, 2005b, p. 145).

Quanto ao ser humano radical a que Paulo Freire se refere, segundo o próprio autor, ser radical é ser consciente, pois "ser consciente é a forma radical de ser dos seres humanos" (FREIRE, 1984, p. 93). "Refiro-me, precisamente, ao papel da consciência na prática da liberdade. [...] Mas sei muito bem que a simples superação da percepção ingênua da realidade por uma crítica não é bastante para que as classes oprimidas se libertem" (FREIRE, 1984, p. 94). Nesse sentido, "o radical rejeita o puro ativismo e submete sempre sua ação à reflexão" (FREIRE, 2005a, p. 59). Implica, portanto, em se libertar, sim, mas não como novos dominadores, pois isso em si, não seria revolucionário, tampouco radical ou dialógico. Do mesmo modo, "a posição radical não pode ser autoflageladora. Não pode acomodar-se passivamente". Esse ser humano radical busca, portanto, o diálogo.

"O homem radical, na sua opção, não nega o direito ao outro de optar. Não pretende impor sua opção. Dialoga sobre ela. Está convencido do seu acerto, mas respeita no outro o direito de também julgar-se certo. Tentar convencer e não converter" (FREIRE 2005a, p. 58). Nesse sentido, o autor propõe a organização como meio de superação do antidialógico, do dicotômico; a mesma organização que também antecede toda a proposta pedagógica críticolibertadora. Dado que essa prática pedagógica freireana, por uma questão de coerência interna, se dá, antes, como um exercício de auto-organização entre aqueles que a utilizam e, somente é consolidada durante o próprio processo dos sujeitos, ou seja, no processo autogestionário e não no processo heterogestionário. Caso contrário, o que se imporia seria, novamente, segundo Freire (2005a), a pedagogia tradicional, ou seja, aquela baseada em relações hierárquicas, antecedida, portanto, por uma organização verticalizada.

É importante salientar, portanto, que na dialogicidade proposta por Freire (2005b), ou seja, na teoria dialógica da ação, defendida pelo autor, "a organização jamais será a justaposição de indivíduos que, gregarizados, se relacionam mecanicisticamente" (FREIRE, 2005, p. 204). O mecanicismo e o hierarquismo, ao contrário, se dão na ação antidialógica. Isto é, enquanto nas práticas organizativas que têm sua orientação na teoria da ação antidialógica os sujeitos se relacionam como conquistadores e conquistados, sendo que o primeiro "conquistando o outro, o transforma em quase coisa, na teoria dialógica da ação, os sujeitos se encontram em "co-laboração". O eu antidialógico, dominador, transforma o tu dominado, conquistado, num mero isto. $\mathrm{O}$ eu dialógico, pelo contrário, sabe que é exatamente o tu que o constituil" (FREIRE, 2005b, p. 191-2).

A atitude do homem é dupla de acordo com a dualidade das palavras-princípio que ele pode proferir. [...] Uma palavraprincípio é o par EU-TU. A outra é o par EU-ISSO [...] A palavra-princípio EU-ISSO não pode jamais ser proferida pelo ser em sua totalidade. A palavra-princípio EU-TU só pode ser proferida pelo ser na sua totalidade. [...] Aquele que diz TU não tem coisa alguma por objeto. [...] Quem diz TU não possui coisa alguma, não possui nada. Ele permanece em relação. [...] O mundo como experiência diz respeito à palavra-princípio EU-ISSO. [...] $\mathrm{O}$ experimentador não participa do mundo: a experiência se realiza 'nele' e não entre ele e o mundo. $\mathrm{O}$ mundo não toma parte da experiência. Ele se deixa experienciar, mas ele nada tem a ver com isso, pois, ele nada faz com isso e nada disso o atinge. [...] Mas a palavra-princípio EU-TU fundamenta o mundo da relação. [...] Relação é reciprocidade. Meu TU atua sobre mim assim como eu atuo sobre ele (BUBER, 1977, p. 3-18).

Nesse sentido, quando Paulo Freire trata da organização entre seres humanos, está afirmando que cada sujeito que constitui essa relação e, portanto, a organização, "sabe também que, constituído por um tu - um não-eu -, esse tu que se constitui, por sua vez, como eu, ao ter no seu eu um tu. Desta forma, o eu e o tu passam a ser, na dialética dessas relações constitutivas, dois tu que se fazem dois eu" (FREIRE, 2005b, p. 192). Não há, portanto, na ação dialógica, um sujeito que domina e um objeto dominado. Em lugar disto, existem sujeitos que se encontram e "colaboram com um objetivo", ou seja, se auto-organizam e aprendem, se conscientizam na própria prática organizativa.

A proposta da pedagogia crítico-libertadora pressupõe que essa conscientização na relação de aprendizagem se dá no processo organizativo, inclusive, na organização da própria 
educação, em uma relação dialógico-problematizadora. Isto é, quando o sujeito questiona o seu 'estar no mundo', seu 'lugar no mundo', ele também questiona o porquê, mas não sozinho, entre outros sujeitos, na organização, mesmo que incipiente e tímida (FREIRE, 1984; 1996). Ao questionar, de acordo com Freire (2005a; 2005b), os sujeitos se (re) posicionam e se auto-organizam para (des)organizar o que está posto e a própria história.

Isso exclui, portanto, a educação tradicional que Freire (2005b, p. 69) denomina de "educação bancária", pois esta anula a capacidade organizativa à medida que afirma o individualismo e considera os sujeitos, especialmente, os marginalizados (oprimidos) "como casos individuais, uma patologia da sociedade sã, que precisa, por isto mesmo, ajustá-los a ela, mudando-lhes a mentalidade de homens ineptos e preguiçosos". De acordo com o autor esse tipo de prática "anula o poder criador dos sujeitos ou, pelo menos, minimiza, estimulando sua ingenuidade e não sua criticidade, pois seu fundamento não é o desnudamento do mundo, a sua transformação". Segundo o autor, tal prática, melhor adapta os sujeitos a uma "desordem organizada", situação de dominação, pois apresenta a sociedade como boa, organizada e justa da qual os indivíduos marginalizados um dia partiram e à qual um dia devem ser incorporados. "Como marginalizados, 'seres fora de' ou 'à margem de', a solução para eles estaria em que fossem 'integrados', 'incorporados' à sociedade sadia”' (FREIRE, 2005 b, p. 70).

$\mathrm{Na}$ verdade, porém, os chamados marginalizados, que são os oprimidos, jamais estiveram 'fora de'. Sempre estiveram 'dentro de'. Dentro da estrutura que os transforma em 'seres para outro'. Sua solução, pois não está em 'integrar-se', em 'incorporar-se'a esta estrutura que os oprime, mas em transformá-la para que possam fazer-se 'seres para si'. (FREIRE, 2005b, p. 70)

É fato, portanto, (1984, p. 89), que "seria na verdade uma atitude ingênua esperar que as classes dominantes desenvolvessem uma forma de educação que proporcionasse às classes dominadas perceber as injustiças sociais de maneira crítica" (FREIRE, 1984, p. 89). Assim, segundo o autor, enquanto na educação 'domesticadora' ou tradicional há uma necessária dicotomia entre os que manipulam e os que são manipulados, na educação libertadora não há sujeitos que libertam e objetos que são libertados. Neste processo não pode haver dicotomia entre seus pólos. Enquanto para Freire (1984, p. 90) “a educação para a domesticação é um ato de transferência de conhecimento, a educação para a libertação é um ato de conhecimento e um método de ação transformadora que os seres humanos devem exercer sobre a realidade".

Numa posição dialética, não é possível aceitar a separação ingênua entre consciência e mundo. Quando o fazemos, caímos ou nas ilusões do idealismo ou nos erros do mecanicismo. [...] o papel da conscientização, um dos ângulos importantes, será o de provocar o reconhecimento do mundo, não como um 'mundo dado', mas como um mundo dinamicamente 'dando-se'. (FREIRE, 1984, p. 94)

Essa conscientização e reconhecimento de que o mundo não está dado, de acordo com o autor, não se dá isoladamente, somente acontece no processo de auto-organização entre os sujeitos e no próprio processo organizativo. "Não se trata obviamente de dizer à população que se rebele, que se mobilize, que se organize para defender-se, para mudar o mundo. Trata-se, na verdade, de desafiar os grupos populares para que percebam, em termos críticos, a violência e a profunda injustiça que caracterizam sua situação concreta" (FREIRE, 1996, p. 48). O autor ressalta que a rebeldia é ponto de partida indispensável, é deflagração da justa ira, mas não é suficiente. A conscientização conduz à rebeldia e esta última, segundo Freire (1996, p. 48), "enquanto denúncia precisa se alongar até uma posição mais radical e crítica, a revolucionária, fundamentalmente anunciadora. A mudança do mundo implica a dialetização entre a denúncia da situação desumanizante e o anúncio de superação. É a partir deste saber fundamental: mudar é difícil, mas é possível", que os sujeitos se organizam e programam uma ação conjunta e organizada e, assim sendo, no processo de organização há continuação do processo de conscientização crítica, de ação e reflexão sobre a ação. Há, portanto, práxis e aprendizagem nessa organização. Nem só ativismo, tampouco só subjetivismo.

Por último, ainda é preciso esclarecer que para Freire (2005b) a ação conjunta e auto-organizada, portanto, dialógica, não implica em ausência de lideranças. "Não significa que no 'quefazer' dialógico não haja lugar para a liderança revolucionária”. Há liderança, há representantes que podem, em determinado momento ser considerados líderes, mas esta "não é proprietária das massas populares, por mais que a ela se tenha que reconhecer um papel importante. A importância de seu papel, contudo, não lhe dá o direito de 
comandar os sujeitos, cegamente, para a sua libertação". Se assim fosse, tal liderança repetiria o messianismo salvador que em nada contribuiria para o processo de aprendizagem auto-organizativa dos sujeitos e de “co-laboração', característica da ação dialógica, que não pode dar-se a não ser entre sujeitos, ainda que tenham níveis distintos de função". Isto posto que a organização dialógica "não impõe, não maneja, não domestica”, age em 'co-laboração', em 'coresponsabilidade’ (FREIRE, 2005b, p. 192-3).

\section{0 contexto dos Movimientos de Trabajadores Desocupados na Argentina}

Os Movimentos de Trabalhadores Desocupados (MTDs) na Argentina têm sua origem mais imediata na década de 1990. Almeyra (2004) lembra que essa crise resultou do acúmulo de decisões políticas, econômicas e sociais que tiveram seu início no final da década de 1950, quando a Argentina converteu-se, quase exclusivamente, em exportadora de carnes e grãos. Tal processo, como primeira consequência, levou à retirada de investimento que o governo fazia, na época, na indústria leve do país e na de produção de bens de capital, para redirecioná-los à indústria de carnes e grãos. "Ali começou a crise argentina que ainda hoje perdura e com ela se agudizou a instabilidade política, dado que os governos depois desse período se lançaram a rebaixar os salários reais e a tentar reduzir a influência do movimento dos trabalhadores" (ALMEYRA, 2004, p. 21).

Nesse contexto, os anos 90, caracterizados como a 'Era Menem' (julho de 1989 a dezembro de 1999), foram parte de um fenômeno considerado como de 'servilismo político', isto é, da utilização da presidência a serviço das demandas e do poder aquisitivo das corporações multinacionais. O legado desse governo: uma economia dependente e vulnerável que poderia entrar em colapso a qualquer instante, além da privatização das principais empresas estatais do país (PETRAS, 2000).

Entre as estatais privatizadas, destaca-se o caso da Yacimientos Petrolíferos Fiscales (YPF), principal produtora de petróleo, cujos trabalhadores constituíam uma espécie de aristocracia operária local. De acordo com Almeyra (2004), quando a YPF foi privatizada houve manifestações em todos os locais onde havia filiais. Foi nesses locais onde a economia girava em torno da YPF que, entre 1996 e 1997, tiveram início as mobilizações que praticamente pararam o país nos anos seguintes. Foram iniciados os movimentos de corte (bloqueio) de ruas e estradas pela população (ZIBECHI, 2003). No mesmo período, outros assalariados do setor público juntaram-se às manifestações. As demandas, em geral, eram pela defesa do emprego e salário, rechaço às medidas de ajustes impostas pelo governo. Usando a mesma estratégia dos petroleiros, bloqueio de ruas e piquetes, outros trabalhadores aderiram aos protestos massivamente com apoio da população (SVAMPA e PEREYRA, 2003).

Nessas manifestações tiveram início "as trajetórias da ação coletiva dos trabalhadores desocupados que produziram mudanças nas relações sociais dos setores populares participantes, introduziram novos significados aos seus vínculos políticos e reposicionaram os aspectos instrumentais da ação social" (DELAMATA, 2004, p. 8). Compreender, a partir dessa dimensão, implica prestar atenção às formas como as organizações resultantes desse processo se relacionaram com as distintas conjunturas e com as iniciativas de políticas públicas para se (re)situarem no espaço político e social. Significa compreender a importância dos seus legados organizativos e as novas ferramentas incorporadas na vida organizacional, bem como a dinâmica que adquiriram os novos mecanismos de tomada de decisão dentro dessas organizações (SVAMPA e PEREYRA, 2003, p. 19).

Os autores destacam como fundamental neste novo tipo de mobilização a consolidação da ideia de que outra identidade e outro destino eram possíveis para quem havia perdido o trabalho. O nome piqueteiro, por sua força expressiva, representava uma alternativa para aqueles definidos como desocupados. Nomear-se piqueteiro teve o poder desestigmatizador, pois a categoria piqueteiro enterrava a de desocupado. Assim, associados à identidade piqueteira e à nova formulação por demandas de trabalho, o bloqueio de vias se consolidou como um formato de protesto que foi utilizado em todo o país (ZIBECHI, 2003).

Os conflitos representaram o ponto
inicial no qual uma nova identidade -
os piqueteiros -, um novo formato de
protesto - o corte (bloqueio) de vias
-, uma nova modalidade organizativa
- a assembleia - e um novo tipo
de demanda - o trabalho - foram
associados, originando uma importante
transformação nos repertórios de
mobilização da sociedade argentina.
(SVAMPA e PEREYRA, 2003, p. 25)

Há que se entender, todavia, que o movimento piqueteiro é heterogêneo e, assim, são heterogêneas suas práticas, ações e objetivos organizacionais. No interior do país, 
onde havia um tecido social relativamente homogêneo, os Movimentos foram quase um só processo. Em Buenos Aires, configuraram-se apenas em alguns bairros - marcadamente naqueles que já tinham experiências de lutas, como a luta em defesa de uma fábrica importante para o bairro, por exemplo; onde já havia um processo de construção de consciência e identidade, de ações coletivas e esforços de auto-organização (ALMEYRA, 2004). A despeito do lugar de origem, Di Fiori (2003) salienta que a construção política dos MTDs se sustenta em três pilares: trabalho territorial, autonomia e horizontalidade. Com base nessas orientações são definidas suas práticas organizacionais.

A reação do governo às mobilizações desses trabalhadores organizados foi a distribuição de planos sociais (uma espécie de 'bolsa família'), a partir de meados de 1997, que garantiriam a assistência alimentar. Alguns MTDs tentaram gerenciar os planos sociais para construir hortas e restaurantes comunitários coletivos de modo a garantir a satisfação das necessidades básicas. Outros criaram pequenos empreendimentos coletivos, tais como, padarias e confecção, com base na utilização dos serviços de membros dos MTDs que recebiam os planos sociais. De modo geral, tentavam produzir no próprio bairro e gerir suas organizações, sobretudo, utilizando práticas organizacionais horizontais (DI FIORI, 2003).

Aqui se dá a diferença entre O Movimiento de Trabajadores Desocupados de La Matanza (MTD de La Matanza) e os outros MTDs, e o define como um caso singular.

O MTD de La Matanza rechaçou os planos sociais por considerálos ferramentas de dominação e de domesticação. Rechaçaram o dinheiro que os institucionalizaria no lugar de pobres sem outro destino que o de dependente estatal. Nesse sentido, a experiência desse grupo permite supor que, desde a sua prática, há saídas que a teoria ainda não capturou. E que como eles mesmos dizem: "em nenhum lugar está escrito que estamos condenados inexoravelmente"

(GIACOBBE, 2006, p. 14-5).

Como tantos outros, o MTD de La Matanza começou a se formar em 1995 e, basicamente, sob as mesmas condições, bem como é constituído por trabalhadores que, passado o primeiro impacto produzido pela sua expulsão do mercado de trabalho, começaram a se reunir para buscar soluções e realizar manifestações (Di MARCO e PALOMINO, 2004). O diferencial desse MTD, portanto, está na não aceitação dos planos sociais distribuídos pelo governo que, segundo a percepção dos membros desse Movimento, os domesticaria, e nos próprios caminhos traçados durante o seu processo organizativo. Devido a essa particularidade esse MTD foi escolhido para ser estudado.

\section{Uma análise Freireana das práticas organizacionais do MTD de La Matanza}

De acordo com Freire (1984, p. 40), "a mudança da percepção da realidade pode dar-se 'antes' da transformação desta, se não se empresta ao termo 'antes' a significação da dimensão estagnada do tempo, com que lhe pode conotar a consciência ingênua". Segundo o autor, o 'antes', como no caso desses trabalhadores, "não significa um momento anterior que estivesse separado do outro por uma fronteira rígida. O 'antes', pelo contrário, faz parte do processo de transformação estrutural". Esta mudança de percepção levou ao rechaço dos planos sociais, porque aqueles trabalhadores começaram a entendê-los como ferramentas de dominação e domesticação: "se deu na problematização de uma realidade conflitiva, implicou num novo enfrentamento dos indivíduos com sua realidade. Implicou na apropriação do contexto, numa inserção nele, num já não ficar 'aderido' a ele; num já não estar sob o tempo, mas nele" (FREIRE, 1984, p. 40). O 'antes' se expressou no não aos planos sociais e, nesse sentido, é parte constituinte fundamental do processo de organização do próprio Movimento.

Como salienta Freire (2005a, p. 114), "toda compreensão de algo corresponde, cedo ou tarde, a uma ação. [...] A natureza da ação, por sua vez, corresponde à natureza da compreensão. Se a compreensão é crítica ou preponderantemente crítica, a ação também o será. Se é mágica a compreensão, mágica será a ação".

A consciência crítica é a representação das coisas e dos fatos como se dão na existência empírica. Nas suas correlações causais e circunstanciais (VIEIRA PINTO apud FREIRE, 2005a, 113). É próprio da consciência crítica a sua integração com a realidade. A consciência mágica capta os fatos, emprestando-lhes um poder superior, que a domina de fora e a que tem, por isso mesmo, de submeter-se com docilidade. É próprio desta consciência o fatalismo. (FREIRE, 2005a, 114) 
No caso desse Movimento, foi um processo lento que teve início no Município de La Matanza que empresta o nome ao MTD. Antes da ação sob o nome de MTD de La Matanza, um grupo de trabalhadores, ocupados e desocupados, desse município começou a se reunir para resolver problemas do bairro onde moravam, La Juanita. Como afirma um dos membros desse MDT, "nos juntamos por uma casualidade, por um problema que houve no bairro. Não podiamos pagar a conta de luz: Cerca de 80\% do bairro tinha esse problema. Estávamos desocupados". Por esse motivo começaram os encontros na casa de um dos moradores - Toty Flores - aos domingos com as pessoas do bairro, amigos do trabalho e vizinhos. Alguns já haviam perdido o trabalho, outros não. " $A s$ primeiras reuniões eram de muita angústia. Cada um contava o que the passava e, ao não ter soluções, era terrivel. Ficávamos muito mal" (Toty Flores). Segundo ele, o primeiro grande "resultado" dessas reuniões foi a "descoberta", entre os sujeitos que ali discutiam, que "o problema não era a luz ou o gás, mas a falta de trabalho. A partir dai as reuniões giraram em torno desse tema e decidimos constituir-nos como uma organização de desocupados, o MTD de La Matanza".

Para Freire (1984, p. 37), esse é o ponto em que o sujeito deixa de apenas mirar a realidade e começa a 'ad-mirá-la': 'ad-mirar' significa adentrar no 'ad-mirado' e mirá-lo “de dentro e desde dentro, o que permite ver. $\mathrm{Na}$ ingenuidade, que é a forma 'desarmada' de enfrentamento com a realidade, apenas miramos e, porque não 'ad-miramos', não podemos mirar o mirado em sua intimidade, o que não nos leva a ver o que foi puramente mirado". Apenas mirar a realidade é ficar na sua periferia e não passar disso. No entanto, a operação de adentramento crítico, a 'ad-miração', implica em posicionamento ativo na realidade; implica em poder optar por uma mudança que "não teme a liberdade, não prescreve, não manipula. Mas rejeitando a prescrição e a manipulação, rejeita igualmente o espontaneísmo" e busca a organização como meio para alterar o que 'ad-mira' (FREIRE, 1984, p. 41).

Para conhecer também o viável histórico, o sujeito precisa "conhecer a realidade em que atua, o sistema de forças que enfrenta" (FREIRE, 1984, p. 41). Segundo Freire (1984, p. 41), isso significa "ter uma compreensão clara das relações entre tática e estratégia, nem sempre, infelizmente, seriamente consideradas".

Esse processo de 'ad-miração' da realidade, na lógica freireana, foi o que, provavelmente, levou aqueles trabalhadores que se reuniam aos domingos a buscar, primeiro, conhecer o próprio bairro: quantos analfabetos, quantos desocupados, principais problemas de infraestrutura. Tal 'ad-miração' da realidade pode conduzir, de acordo com Freire (1984), a um processo de organização entre os sujeitos que implica em práticas organizacionais não hierárquicas, como no caso do MTD de La Matanza, a começar das reuniões que realizavam. De acordo com Jorge Lasarte, um dos membros do MTD de La Matanza, "era uma coisa absolutamente diferente, uma novidade. Todo mundo participava na discussão, mas o que tinha de interessante era que os companheiros estavam dispostos a modificar o que pensavam e a reunião terminava com um acordo. Nem maioria, nem minoria, era um acordo em consenso e, às vezes, não. Depois seguia a discussão na próxima reunião ou no transcurso da semana se resolvia [...]. Não era algo que alguém dizia: bom, agora vamos fazer tal coisa e os demais faziam. Não, tudo se discutia. [...] às vezes as vozes se levantavam, mas depois da reunião ficava tudo bem porque havíamos concordado de alguma maneira.

Freire (1984; 2005a) entende esses primeiros passos como uma tentativa de começar a 'pronunciar' o mundo, de agir e refletir sobre a ação; sem subjetivismo, per si, tampouco ativismo ou objetivismo, em si, mas práxis. $\mathrm{O}$ sujeito começa a deixar a simples acomodação no mundo, o ajustamento que o submete às prescrições alheias e que minimizam suas decisões, decisões que já não suas porque resultam de comandos estranhos, e passa a integrar-se ao mundo. Isto é, ao invés de acomodação, se dá a integração, um tipo de ajustamento ao mundo que pressupõe capacidade de transformá-lo na medida em que o sujeito pode optar e pode decidir, posto que a capacidade de integração se aperfeiçoa a medida que a consciência se torna crítica. Assim, na medida em que cria, recria e decide, pode conformar as épocas históricas. A esse respeito, Freire (2005a, p. 51) ainda afirma que:

Uma das grandes, se não a maior tragédia do homem moderno, [...] está em que vem sendo expulso da órbita das decisões. As tarefas do seu tempo não são captadas pelo homem simples, mas a ele apresentadas por uma 'elite' que as interpreta e as entrega em forma de receita, de prescrição a ser seguida. $\mathrm{E}$, quando julga que se salva seguindo as prescrições, [...] é domesticado e acomodado: já não é sujeito. Rebaixase a puro objeto. Coisifica-se.

Nesse sentido, desde as primeiras reuniões do MTD de La Matanza, a ação dos sujeitos se deu/dá na direção da integração, da busca de tornarem-se sujeitos no mundo, não mais meros objetos. Freire (2005b) também destaca que quando se dá esse nível de conscientização, passa a existir a impossibilidade de retomar sua condição anterior. 
"Transitamos todos os caminhos por onde foram os piqueteiros. Os Movimentos no seu início eram absolutamente autônomos. Não respondiam a partidos políticos, nem a sindicatos. Eram parte de um processo genuíno de auto-organização da 'gente' que havia ficado sem trabalho e suas reivindicações tinham a ver somente com trabalho. Tudo o que estava relacionado com o trabalho como forma de vida. Na crise econômica na Argentina, eximiram os empresários de pagar impostos para que dessem trabalho, eximiram os bancos, mas os trabalhadores não foram eximidos de nada. Tinham que seguir pagando luz gás [...]. Assim, no inicio, compartilhávamos pequenos trabalhos; trabalhávamos a terra porque nos parecia que se podia solucionar o problema da fome no bairro com algumas hortas comunitárias e fazendo alguns empreendimentos" (Toty Flores).

Como já afirmado anteriormente, Freire (1996; 2005b) salienta esse processo organizativo como imprescindível para a práxis emancipadora, pois é em meio a esse processo que se dá a aprendizagem. O autor salienta, ainda, que não há um indivíduo que ensine os outros e tampouco que a aprendizagem e a conscientização sejam iguais e se deem ao mesmo tempo para todos envolvidos no processo. $\mathrm{O}$ processo organizacional facilita a aprendizagem porque a descoberta de um é complementada pela de outro e o mesmo se dá com as práticas, que são modificadas pelos sujeitos que aprendem na auto-organização e que, nesse processo, enfrentam em si mesmos a culpa e o medo.

Nesse sentido, Freire (2005b, p. 164) destaca que os sujeitos sabem, por experiência, o quanto lhes custa: "a perda do emprego e ter seu nome numa 'lista negra', que significa portas que se fecham a eles para novos empregos e isso é o que lhes pode suceder. A sua insegurança vital, por isto mesmo, se encontra diretamente ligada à escravização de sua pessoa." Assim, segundo o autor, enquanto esses sujeitos não descobrem que "são presas do dirigismo e da dominação" porque não se organizam, os dirigentes se encarregam de repetir a história, apenas refazendo as nomeações através de manipulações e reforçando a culpa e o medo. Freire (2005b, p. 168) afirma que "a manipulação aparece como uma necessidade imperiosa dos dominadores, com o fim de, através dela, conseguir um tipo 'inautêntico' de organização, com que evita o seu contrário, que é a verdadeira organização”.

$\mathrm{Na}$ organização que resulta do ato manipulador, as massas populares, meros objetos dirigidos, se acomodam às finalidades dos manipuladores enquanto na organização verdadeira, em que os indivíduos são sujeitos do ato de organizar-se, as finalidades não são impostas por uma elite.
No primeiro caso, a organização é meio de massificação; no segundo, de libertação. (FREIRE, 2005b, p. 168)

O que se observou no MTD de La Matanza, de acordo com Toty Flores, foi essa questão destacada por Freire (2005b), pois o maior problema para os desocupados foi enfrentar a si mesmo, pois parecia ao desocupado que a responsabilidade de não ter trabalho era sempre e unicamente dele. "Culpado por ter ficado por distintos motivos. [...] Não se visualizava que um grupo minoritário de indivíduos que governavam o mundo havia decidido deixar à deriva milhões de pessoas. A culpa impede de organizar-se com outros para, entre todos, encontrar uma solução aos problemas" (FLORES, 2005, p. 15). O medo, segundo o autor, contribuía para imobilizar os trabalhadores. Medo da derrota, pois já haviam sido derrotados em vários terrenos: no campo econômico, no campo político, no campo ideológico e, inclusive, no campo moral. A combinação culpa e medo, segundo Toty Flores (2005), dificultava a formulação, mesmo que eventualmente, de respostas aos seus próprios problemas. Esses problemas foram combatidos com política e com auto-organização, embora tenha sido um processo lento.

Esse processo 'lento', segundo Freire (1997), é sustentado pelas relações estabelecidas entre sujeitos coletivos. Nesse caso, a aprendizagem na prática organizacional vai além do núcleo de 'um' coletivo, ela se dá entre coletivos. Uma relação dialógica que contribui positivamente para que um sujeito vá sendo o artífice de sua formação com a ajuda necessária de outro sujeito (FREIRE, 1997, p. 42). Nessa relação, de acordo com Freire (1997, p. 42), o papel de um sujeito na formação do outro é estar "atento à difícil passagem ou caminhada da heteronomia para a autonomia, atento à responsabilidade da sua presença que tanto pode ser auxiliadora como pode virar perturbadora da busca inquieta do outro". Nessa associação, o autor salienta como fundamental o convencimento do outro, o respeito à decisão do outro, mas sem desconhecer o posicionamento político daquele que tentar convencer.

Primordialmente minha posição tem de ser a de respeito à pessoa que queira mudar ou que recuse mudar. Não posso negar-lhe ou esconder-lhe minha postura, mas não posso desconhecer o seu direito de rejeitá-la. Em nome do respeito, não tenho por que me omitir, por que ocultar a minha opção política assumindo uma neutralidade que não existe. [...] O meu papel, ao contrário, 
é o de quem testemunha o direito de comparar, de escolher, de romper, de decidir por parte do outro. (FREIRE, 1997, p. 42)

No processo de organização do MTD de La Matanza, isso significou a aproximação de outros movimentos sociais: de outros MTDs e, de um modo especial, das Mães da Praça de Maio. Até meados de 1997, o MTD de La Matanza cresceu em número de integrantes e se aproximou, principalmente, de outros MTDs. Porém, a partir desta data, quando ocorreu o início da distribuição dos planos sociais, a história desse coletivo passou por uma ruptura profunda que o distanciou, pelo menos parcialmente, de outros MTDs. Flores (2006) afirma que, quando o governo anunciou a distribuição de planos sociais, inicialmente comemoraram, mas depois, em discussões com as Mães da Praça de Maio, entenderam que os planos mais uma vez iam impor a cultura da sobrevivência, a dependência do Estado. Essa 'co-laboração', a associação do MTD de La Matanza com as Mães da Praça de Maio, foi fundamental para o posicionamento político-organizacional do Movimento.

A relação dialógica entre os participantes das Mães da Praça de Maio e do MTD de La Matanza, bem como dentro do próprio MTD, foi um dos fatores que levou à reorganização do Movimento. Alguns sujeitos compreenderam que os planos não contribuiriam para sua auto-organização, mas para manutenção da dominação, outros não. $\mathrm{Na}$ época, esses últimos se desligaram do MTD de La Matanza e se vincularam a outros MTDs, tornando aquele grupo muito reduzido.

Ao mesmo tempo em que recusaram os planos sociais, deram início a um processo continuado de aprendizagem junto à Associação Mães da Praça de Maio. Com as Mães decidiram continuar a luta junto aos outros MTDs e às demais organizações dos trabalhadores. Embora adotando uma postura diferente com relação à sua própria manutenção e organização (FLORES, 2006, p. 23). De acordo com Soledad Bodegaray, membro do MTD de La Matanza, "a partir dali o Movimento tomou novos rumos. Foi uma escolha de longo prazo. [...] Começamos a nos reconstruir. Foi o ano mais duro da nossa construção. Os companheiros se dispersaram e houve muita discussão interna. Então, comecamos por organiz̧ar o nosso próprio núcleo".

Esse núcleo que começou a se reorganizar e acolheu novos membros é que constitui, atualmente, o MTD de La Matanza. Um Movimento que nasceu da autoorganização da própria luta. De uma escolha política em assumir a direção da própria vida. Em estreita associação, livre e autônoma, com as Mães da Praça de Maio que, nos primeiros anos, compartilharam seu saber e experiência com aqueles que davam os primeiros passos rumo à auto-organização ou autogestão. Uma prática que "não constitui nenhum imperativo ideológico; pois ela tem sua legitimidade na medida em que surge da reivindicação do movimento real" (TRAGTENBERG, 1987, p. 31), isto posto que para autogerir alguma coisa, segundo o autor, é preciso começar autogerindo a própria luta.

Assim entendido que, se os sujeitos sociais são capazes de organizar, de modo autônomo e coletivo, diretamente a própria luta, então, serão capazes também de organizar a produção e a mudança social. A luta, de acordo com Tragtenberg (1987), é o embrião do que virá, é o exercício da organização; é o começo da viabilização prática do estabelecimento de relações sociais coletivistas. Como salienta Rosa Luxemburgo, nesse momento o papel de dirigente seria ocupado pelo "eu coletivo da classe operária, que reclama resolutamente o direito de cometer ela mesma os equívocos e de aprender por si só a dialética da história" (LUXEMBURGO e LÊNIN, 1985, p. 39).

Freire (1996) ainda ressalta que não é possível um indivíduo se assumir como sujeito da própria procura, da decisão, da ruptura, da opção, a não ser assumindo-se como sujeito histórico, transformador, ou seja, reconhecendo e assumindo seu viável histórico, mas isso só pode ser feito entre outros sujeitos, na organização, na prática organizacional.

No processo organizacional do MTD de La Matanza, segundo Toty Flores, um dos membros do Movimento, a aprendizagem em 'co-laboração' com as Mães da Praça de Maio foi ímpar, pois os sujeitos que compunham o Movimento começaram a perceber novas possibilidades. $\mathrm{O}$ ponto de partida foi criar um Centro Comunitário no seu bairro, La Juanita, "foi o primeiro trabalho territorial'. Também colaboraram com as atividades das Mães da Praça de Maio, ajudaram na construção da Universidade Popular das Mães da Praça de Maio e essa atitude contribuiu ainda de outra maneira: tornou visível o MTD de La Matanza como nunca haviam imaginado. O Trabalho em 'co-laboração' com as Mães da Praça de Maio apresentou-se como uma relação de ensino-aprendizagem singular.

O Centro Comunitário do bairro se encheu de pensamento; muitas pessoas vinham falar na rádio comunitária do Centro; importantes pensadores comprometidos com a causa popular vinham e ficavam 
para participar das conversas de domingo e compartilhamos seus saberes. Pela primeira vez incorporei conscientemente a necessidade da coerência entre o pensar, o sentir e o fazer. Desde então, assumimos o compromisso de incorporar a 'pedagogia do oprimido' [numa referência a Paulo Freire] em cada ato educativo do nosso movimento (FLORES, 2005, p. 34).

Somente em 1999, devido à situação na qual se encontravam vários membros do grupo, começamos a pensar em desenvolver um projeto mais concreto. Assim, as discussões passaram a ser mais pontuadas em torno da questão de buscar manter a própria sustentabilidade (Jorge Lasarte). Muitas ideias foram discutidas, até que as pessoas começaram a pensar possibilidades que pudessem viabilizar dentro do próprio bairro. Realizaram feiras de gêneros alimentícios e vestuários, principalmente, para intercambiar produtos, três vezes por semana, bem como o plantio coletivo de hortas. Entretanto, as ideias não prosperaram por falta de organização entre as pessoas. Não sabiamos como nos organizar coletivamente para viver de um empreendimento (Jorge Lasarte). A prática de organização se reduzia às reuniões.

Decidimos, então, voltar nosso esforço na busca de alianças com quem teria o 'poder do conhecimento teórico' e nos atribuímos a tarefa de visitar e de nos aproximar das universidades. [...] Os jovens nos perguntavam de tudo, o que nos surpreendeu muitíssimo, pois na realidade nós queríamos que eles respondessem nossas dúvidas. Então, nos demos conta que nos movimentos sociais também há saberes, que não os desenvolvemos porque a cultura nos ensina que quem está acima sabe e os demais não. [...] Tínhamos medo de levar lá nossas discussões, que eram muito emotivas e porque também sabíamos que dizíamos muita coisa errada. Porém, fomos às faculdades, participamos de alguns seminários, conversas, debates etc., e isso nos animou bastante porque vimos que também nos claustros acadêmicos se diz muita bobagem, com a diferença que as dizem com nível. (FLORES, 2005, p. 16-21)
Nessa prática organizacional, na formação de alianças, que se dá na 'co-laboração', o sujeito aprende com outro sem que haja um processo de subordinação. No coletivo, ao 'co-laborar', re-elaboram o mundo e, ao reconstruílo, percebem que também são construídos por ele e, reflexivamente, retomam o movimento da consciência que os constitui sujeitos na construção histórica (FREIRE, 2005b). Ao fazê-lo, aprendem e produzem conhecimento.

Além do apoio das Mães da Praça de Maio, fizeram novas alianças. Segundo Toty Flores, durante o período que trabalharam com as Mães iniciaram uma aproximação com outras organizações: "no início, foram difíceis as discussões com as organizações". Segundo Soledad Bodegaray, "outras organizações compartilharam seus conhecimentos para fortalecer-nos, para enriquecer nossa prática. Não foi fácil para elas, nem para nós. Construir na diversidade de critérios, de estratégias, de códigos e às vezes, até de objetivos, é um desafio". Mas é uma prática que fortalece o grupo.

Até 2001, os membros do MTD de La Matanza dedicaramse à formação de alianças com o objetivo principal de aprender a se organizar para manter a produção e reprodução da própria vida e, principalmente, manter um empreendimento que viabilizasse a sustentabilidade do grupo. O primeiro grande resultado das alianças e discussões entre os membros do próprio MTD foi a elaboração de um 'plano', cujo foco estava na educação e na tomada de consciência que as mudanças que almejavam deveriam ter início no local onde moravam (FLORES, 2005). A questão agora não era somente aprender a gerir a própria organização, gerir o Movimento, os próprios empreendimentos, mas entender a gestão e compreender a organização como um meio para atingir os objetivos do MTD de La Matanza.

O 'plano' formulado por esse coletivo fazia parte do processo de formação de uma cooperativa de trabalho cujo principal objetivo era criar e manter uma escola, do próprio MTD, que atendesse a comunidade do seu bairro. A partir de então, "voltaram o olhar" para La Matanza e começaram a construir e transformar a partir do bairro. Em 2002 realizaram cursos e seminários, com o objetivo oferecer aos vizinhos e a si mesmos a capacitação que permitisse o surgimento de projetos de autogestão comunitária e a formação de uma cultura organizativa baseada na cooperação, como parte de uma estratégia que levasse à produção de mudanças qualitativas na concepção do político e social (Di MARCO e PALOMINO, 2004, p. 65).

Segundo Toty Flores, os resultados foram excelentes, porque muitas pessoas queriam conhecer, inclusive colaborar, com a concretização dos planos dos MTD de 
La Matanza. Soledad Bodegaray foi uma dessas pessoas que chegou ao Movimento para conhecer e, atualmente, é membro do MTD. A partir de então, aquele pequeno grupo, que começou a se reinventar após a renúncia aos planos sociais, passou a efetivar alguns de seus planos. Todavia, ainda faltava o espaço físico e a formalização jurídica. Decidiram primeiro procurar um espaço maior que pudesse comportar os empreendimentos que já vinham desenvolvendo no Centro Comunitário. $\mathrm{Na}$ época, uma serigrafia, uma pequena confecção e uma editora que, naquele momento, já havia editado dois livros relacionados à história do Movimento, seus encontros e desencontros: " $1{ }^{\circ}$ Foro Social Mundial: desde los desocupados" e "De la culpa a la autogestión: un recorrido del Movimiento de Trabajadores Desocupados de La Matanza”, organizados por Toty Flores.

Procuraram um local no próprio bairro e decidiram pela ocupação do prédio de uma antiga escola particular fechada devido à crise econômica que atravessou o país. Assim, no dia 16 de setembro, ocuparam, de fato, o prédio situado na Rua Juan B. Justo, 4650, no bairro La Juanita. "Nós tínhamos um centro comunitário pequeno, perto daqui, e sempre víamos esta escola e diríamos: não pode ser, nós temos um projeto [...] e este espaço vazio aí. Tomamos a escola e apresentamos o projeto que tínhamos em vários lugares e o único que nos deu 'bola' foi o Instituto Movilizador de Fondos Cooperativos" (Sílvia, membro do MTD).

Passaram, então, a se dedicar aos empreendimentos que já vinham desenvolvendo, agora profissionalmente, de modo que no longo prazo, também pudessem sustentar a escola que pretendiam criar. Por exemplo, a princípio, a pequena confecção produzia peças com pouca qualidade e que só eram vendidas nas feiras do bairro. Trataram, então, de buscar costureiras profissionais no próprio bairro que pudessem ensinar o ofício a outras e, assim, obter recursos da confecção. Ao mesmo tempo, com a convicção de que poderiam concretizar a escola que planejavam, buscaram alianças com a comunidade, de modo que essa pudesse participar ativamente da formatação e concretização da escola. Antes de concretizar a escola, o MTD criou e aprendeu a gerir, primeiro, seus empreendimentos produtivos, cuja parte dos ganhos é usada para mantê-la.

Importante destacar que as pessoas, no MTD de La Matanza, se referem às suas atividades como 'produtivas' ou 'educativas'. As atividades que fazem parte do que eles denominam de complexo produtivo são: padaria, confecção, serigrafia, editora. Do complexo educativo fazem parte as atividades de teatro, a escola, educação para jovens e adultos, o ensino técnico. Cada um desses complexos tem um coordenador geral e cada empreendimento um coordenador, além dos coordenadores administrativos que cuidam dos assuntos da comunidade. A presença dos coordenadores é uma constante nas reuniões agendadas, mas existem ou são chamadas reuniões, a qualquer tempo, para tratar de qualquer assunto. Desde a definição das estratégias da Cooperativa para o semestre seguinte, até discutir quem vai ficar com uma camiseta. Há também reuniões por empreendimentos ou por atividades. Por exemplo: reuniões somente do coletivo da confecção; do coletivo da escola; só de coordenadores; do coletivo que atua mais fortemente nos problemas do bairro, como limpeza, saúde entre outros; e de outro coletivo, cuja função é reivindicar junto aos órgãos públicos competentes a instalação de infra-estrutura no bairro La Juanita, com apoio da comunidade.

Normalmente, as reuniões começam com conversas informais e brincadeiras que consomem certo tempo até que seja dado início às discussões do dia. Os coordenadores gerais iniciam a reunião informando o conteúdo da pauta que foi definido, entre todos, ao longo da semana, de acordo com os acontecimentos. Assuntos pendentes, problemas de relacionamento, problemas nos empreendimentos, prestação de contas das atividades que as pessoas ou grupos ficaram responsáveis por realizar, definição de novas tarefas, estratégias, enfim, o que as pessoas sugerirem para discussão. Os demais coordenadores, se têm um assunto pertinente ao empreendimento pelo qual respondem ou por uma tarefa específica da qual ficaram encarregados, também informam a todos do que vão tratar. Se alguém mais quiser acrescentar um tema para discutir com o coletivo, também o faz a qualquer momento.

Geralmente, aquela pessoa que inicia a reunião é a responsável por sua condução até o fechamento. Distribui as falas, interrompe as palavras dos que tentam monopolizar ou que começam a tratar de assunto sem valor para aquela sessão ou as conversas paralelas, bem como solicita que uma pessoa discorra sobre determinado tema. Embora a pessoa exerça a atividade de coordenação da reunião, o faz com a ajuda dos presentes, pois esses também solicitam silêncio dos outros, informam que um colega está falando demais ou lembram assuntos a ser tratados.

As reuniões duram horas e, se não chegam a um acordo, marcam nova reunião para o dia seguinte. Essa é uma das práticas mais marcantes do MTD de La Matanza: a utilização do consenso para a tomada de decisão. Assim, todos são sabedores das decisões e estão implicados na concretização do que foi decidido. Muitas pessoas fazem anotações durante as sessões, mas uma, geralmente um dos coordenadores e nunca quem conduz a reunião, é chamada a fazer a leitura das anotações. A partir dali, começam a debater novamente e, então, elaboram uma proposta. Às vezes, são retomadas as anotações e acrescentadas outras. 
Algumas vezes param e retomam no dia seguinte. Depende da demanda de trabalho da Cooperativa. Do início ao encerramento de determinado assunto podem se passar dias. Um exemplo de como os assuntos são tratados é apresentado a seguir.

$\mathrm{O}$ preço das camisas que exportam estava alto em comparação com outras do mesmo padrão. Na primeira reunião discutiram os motivos desse preço; mesmo aqueles que não trabalham na confecção. Foram 'imaginadas' várias explicações: preço dos fornecedores, preço da hora trabalhada, falta de máquinas, ritmo de trabalho lento, muito retrabalho, entre outros. A cada sugestão e, dependendo de quem viesse, passavam horas discutindo. Foram alguns dias de discussão, até que convidaram a pessoa que trata diretamente com o comprador na Itália para explicar a composição do preço. Em meio a apresentações da composição do preço das camisas, muitos gráficos que explicavam que cada atraso significava aumento nesse preço, porque ao invés de enviar as encomendas via marítima ( $5 \%$ do preço da camisa) teriam que enviar via aérea ( $17 \%$ do preço da camisa) ... muitas anotações, perguntas e comentários ... que parar muitas vezes significava preço mais alto ... marcaram outra reunião para discutir o que tinha sido apresentado. Mais algumas reuniões depois: porque não poderiam pagar por peça, como é comum, dado que para atender a essa demanda específica tinham que trabalhar em linha e que tampouco poderiam controlar a quantidade de vezes que cada pessoa parava, decidiram, então, que cada um iria anotar, em uma ficha, a sua produção diária e, assim, verificar, junto com a coordenadora como estava seu ritmo de trabalho. Algumas ficavam até mais tarde ou chegavam mais cedo para ajudar as companheiras, outras cumpriam somente seu horário de trabalho, nada mais. Mas assim, decidiram algo que estava bem para todos.

Em outro caso, quando o assunto é urgente e diz respeito a um dos empreendimentos da Cooperativa, embora todos sejam chamados para tomar conhecimento do que está acontecendo, é o coordenador daquele empreendimento, com apoio da Comissão Diretiva que toma a decisão. Um desses casos: o fornecedor dos "cortes" com os quais a confecção do MTD de La Matanza faz as camisas que a Cooperativa exporta perdeu o principal 'cortador' para outra empresa. O fornecedor é uma empresa recuperada e junto com o MTD de La Matanza tinham financiado o treinamento de duas pessoas para esse tipo de corte. Uma da empresa recuperada e outra do MTD que, coincidentemente era uma das coordenadoras da confecção. Imediatamente a Comissão Diretiva decidiu, com a anuência dessa coordenadora, que ela iria trabalhar durante uns dias naquela empresa, em outra cidade, até resolverem o problema. Os outros membros do MTD de La Matanza foram chamados para uma reunião no mesmo dia e depois de Toty Flores relatar o fato, comunicou a decisão tomada. Não houve problemas associados à questão.

Acerca desse tipo de decisão, tomada sem a anuência imediata de todos, Freire (2005b) salienta que há que se ter o cuidado para que elas não se tornem rotineiras e "tomem ares de naturais" exacerbando tais líderes quando, de fato, são meros representantes. De acordo com Freire (2005b, p. 162), se verifica uma situação limite "nos chamados treinamentos de líderes que, embora quando realizados sem esta intenção por muitos dos que os praticam, servem, no fundo, à alienação. O básico pressuposto desta ação já é, em si, ingênuo". Caso sejam promovidos a naturais e 'necessários', processos decisórios que excluem parte dos sujeitos da organização, e admitidos líderes com plenos poderes, "sua tendência, provavelmente, será, para não perderem a liderança, continuar, agora, com mais eficiência, no manejo da comunidade". Todavia, como já salientado, o cuidado constante dos próprios integrantes da organização para que ela não se verticalize através da adoção de líderes inamovíveis não implica em ausência de lideranças. Significa, apenas, que os líderes não são proprietários da organização ou senhores do processo organizacional, uma vez que a organização dialógica "não impõe, não maneja, não domestica", age em 'co-laboração', em 'co-responsabilidade' (FREIRE, 2005b, p. 162 e 192-3).

Outra prática do MTD de La Matanza é contar a própria história. É constante. A cada reunião são reforçados os princípios e valores com os quais começaram, como a solidariedade e o trabalho coletivo. São lembrados os primeiros passos dados e os objetivos que ainda pretendem realizar. Esta prática independe da existência ou não de pessoas que estão lá pela primeira vez. Nas conversas informais a temática também é recorrente, principalmente lembrando a história das primeiras reuniões e das pessoas que decidiram romper com a lógica do assistencialismo e da dependência. Os conflitos, de forma predominante, também são resolvidos recorrendo à história da organização. Isto é, à sua história de luta e superação de obstáculos que foram enfrentados com base na solidariedade existente entre os membros do Movimento. Todos os conflitos são discutidos nas reuniões, em meio a todos. Se não são resolvidos, outra reunião é chamada, exclusivamente com esse fim.

Desse modo, de acordo com Freire (2005b, p. 79), todos se educam no diálogo e "se tornam sujeitos do processo em que crescem juntos e em que os argumentos de autoridade já não valem [...] os homens se educam em comunhão, 
mediatizados pelo mundo", auto-organizados. Freire (2005b) ainda ressalta que recorrer ao próprio processo de auto-construção, de auto-conscientização, reforça nos sujeitos a certeza que a realidade não está dada, que é possível de ser transformada através da ação e reflexão sobre a ação, pela práxis e aprendizagem na organização. "Foi sua inserção lúcida na realidade, na situação histórica que levou à crítica desta mesma situação e ao ímpeto de transformá-la" (FREIRE, 2005b, p. 61). Para continuarem como sujeitos da própria organização e não se tornarem objetos no decorrer do tempo ou verticalizarem-se, o autor salienta que é preciso criticar/pensar continuamente a própria organização. Esse processo de autocrítica e reconhecimentos dos 'quefazeres' dialógicos ou antidialógicos se dá nas práticas organizativas dos sujeitos ou no processo organizacional que tem lugar na ação dialógica, sendo, em sua essência, aprendizagem.

Depois que as decisões são tomadas, cada coordenador é responsável pelas atividades do empreendimento pelo qual responde e, conseqüentemente, pelas atividades das pessoas que coordena, e essas responsáveis por suas tarefas. Isto é, há co-responsabilidade na tomada de decisão e na execução das tarefas. "É uma luta diária para todo mundo ser responsável por sua atividade[...] Tem que ter paciência. Demora, mesmo. Foi muito tempo só obedecendo. Deve precisar de muito tempo para aprender a decidir. [...] Assim, ficar cobrando que as tarefas sejam realizadas é uma das atividades do coordenador" (Toty Flores).

É importante ressaltar, ainda, que as atividades de coordenação não são exclusivas. São realizadas por alguém com alguma função específica no empreendimento. A realização das tarefas específicas, por sua vez, depende de cada empreendimento e de como as pessoas se ajustam entre si. Para a confecção, por exemplo, selecionar novos profissionais não é tarefa exclusiva da coordenadora. Qualquer costureira pode passar o dia acompanhando uma candidata e, ao final, mostrar para as outras o trabalho dela. Então, decidem se a candidata pode ficar ou não. Em outros casos, quando não há urgência, podem treinar uma pessoa na própria confecção. $\mathrm{O}$ mesmo acontece nos outros empreendimentos.

Outra prática da Cooperativa diz respeito ao acompanhamento dos trabalhos realizados rotineiramente: as tarefas realizadas são acompanhadas pelo coordenador do empreendimento e pelos próprios colegas, que podem devolver um 'trabalho' considerado mal feito. Inclusive um trabalho feito pelo coordenador. Todos analisam as tarefas de todos em cada empreendimento. Essa prática também é motivo de conflito, levando alguns a sair da Cooperativa, mas os que lá continuam acreditam que essa é a melhor maneira de fazer.
Nenhuma pessoa que trabalha em um empreendimento pode interferir na tarefa de um cooperado de outro empreendimento. Tanto que durante o expediente não se observa, no local de trabalho, pessoas que ali não tenham tarefas a cumprir. A não ser que seja convidada para tanto e com alguma tarefa específica. Outra possibilidade é durante as reuniões gerais, onde cada coordenador presta contas do empreendimento pelo qual é responsável. Nesse momento todos podem interferir, pedir explicações e dar sugestões. "As pessoas demoram a se acostumar a ver seus trabalhos sendo avaliados pelos próprios colegas. Muitos não gostam disso, mas são avisados quando veem trabalhar aqui. Quem fica é porque gosta e depois tem que decidir se vai ser cooperado ou não. Tem gente que também não gosta e alguns vão embora por causa disso" (Silvia).

\section{Considerações finais}

Antes de concluir é preciso ressaltar que a lógica fundamental desses empreendimentos é baseada nos seguintes critérios: manter a fonte de renda, a autosustentação e, por conseguinte, das respectivas famílias, bem como a solidariedade para com a comunidade do bairro La Juanita. Por exemplo: em um determinado período, o saco de farinha de trigo aumentou tanto em menos de um ano que o quilo de pão passou de 1,20 pesos para 3,00 pesos nas padarias do bairro. Como na Panaderia La Masa Crítica, trabalhavam somente duas pessoas, elas decidiram que poderiam manter os preços anteriores, embora isso acarretasse diminuição na sua renda. A decisão daquele empreendimento foi levada para uma reunião, apoiada por todos, e o preço foi mantido.

Ainda é preciso ressaltar, veementemente, como afirma Jorge Lasarte (2007, p. 5), que o "MTD de La Matanza considera que a educação e a produção são coisas indissolúveis para a formação de sujeitos de direito". De acordo com o autor, a diferença está em que "a educação e o trabalho que esse MTD propõe têm uma forte modificação na metodologia com que são levados adiante. O MTD de La Matanza crê que no trabalho, assim como na educação, o que deve ser modificado são as relações de poder" (LASARTE, 2007, p. 5).

Essa proposta é coerente com as ideias de Paulo Freire: mudar as relações de poder na organização; ao invés do verticalismo que organiza a relação ensino-aprendizagem, o horizontalismo. A auto-organização, inerente ao processo de ensino-aprendizagem, se efetiva como um exercício entre aqueles que a vivem e somente se consolida no próprio processo realizado pelos sujeitos. Isto é, a organização é meio e processo de aprendizagem para a 
práxis emancipadora, posto que a concepção freireana acerca de uma 'pedagogia libertadora' entende como inseparáveis a prática organizacional e o processo de ensino-aprendizagem.

É importante, portanto, reafirmar que na teoria dialógica da ação, defendida por Paulo Freire, "a organização jamais será a justaposição de indivíduos que, gregarizados, se relacionam mecanicisticamente", uma vez que tal processo é imprescindível para a práxis emancipadora, pois é em meio a esse processo que se dá a aprendizagem. (FREIRE, 2005b, p. 204). Não há, portanto, na ação dialógica, um sujeito que domina e um objeto dominado. Em lugar disto, existem sujeitos que se encontram e "co-laboram com um objetivo", ou seja, se auto-organizam e aprendem no processo de auto-organização, se conscientizam na própria prática organizativa. Assim, aqueles que utilizam a organização como meio e aprendizagem para a práxis emancipadora, rejeitam, portanto, "a prescrição e a manipulação, rejeitam igualmente o espontaneísmo”, e buscam a organização como meio para alterar o que 'ad-miram' (FREIRE, 1984, p. 41). Nesse sentido, nesse processo de organização há um processo de conscientização crítica, de ação e reflexão sobre a ação. Há, portanto, práxis e aprendizagem nessa organização. Nem só ativismo, tampouco só subjetivismo. A vivência no coletivo do MTD de La Matanza permitiu não apenas aprender com sua organização, mas também provocou o retorno aos textos de Paulo Freire e, a partir desse encontro, novas aprendizagens.

\section{Referências}

ALMEYRA, Guillermo. La protesta social en la Argentina (1999-2004). Buenos Aires: Ediciones Continente, 2004.

ANGROSINO, Michael.V.; PÉREZ, Kimberly M. de. Rethinking Observation: from Method to Context. In: DENZIN, Norman K., LINCOLN, Yvonna S. Handbook of Qualitative Research. Thousand Oaks, Sage Publications, 2000. p. 107-153.

BUBER, Martin. Eu e tu. São Paulo: Cortez \& Moraes, 1977.

DELAMATA, Gabriela. Los barrios desbordados: las organizacionaes de desocupados del Gran Buenos Aires. Buenos Aires: Eudeba, 2004.

DI FIORI, Vladimir. Paríendo nuevas prácticas. 2003. Disponível em http://www.solidaridadesrebeldes. kolgados.com.ar. Acesso em 9 jan. de 2008.
DI MARCO, Graciela; PALOMINO, Héctor (Orgs.) Construyendo sociedad y política: los proyectos del movimiento social en acción. Buenos Aires: Ediciones Baudino, 2004.

FREIRE, Paulo. Ação cultural para a liberdade. Rio de Janeiro: Paz e Terra, 1984.

FREIRE, Paulo. Pedagogia da Autonomia: saberes necessários à prática educativa. Rio de Janeiro: Paz e Terra, 1996.

FREIRE, Paulo. Educação como prática da liberdade. Rio de Janeiro: Paz e Terra, 2005a.

FREIRE, Paulo. Pedagogia do oprimido. Rio de Janeiro: Paz e Terra, 2005b.

FLORES, Toty. De la culpa a la autogestión: un recorrido del Movimiento de Trabajadores Desocupados de La Matanza. Buenos Aires: Ediciones Continente, 2005.

FLORES, Toty. Cuando com otros somos nosotros: la experiencia asociativa del MTD de La Matanza. Buenos Aires: MTD Editora, 2006.

GIACOBBE, J. Prólogo. In: FLORES, Toty (Org.). Cuando com otros somos nosotros: la experiencia asociativa del MTD de La Matanza. Buenos Aires: MTD Editora, 2006. p. 11-15.

LASARTE, Jorge. Introducción. In: MTD de La Matanza; DOBIN-BERNSTEIN, Noah. La Massa Crítica: libro de recetas de la Panaderia Comunitária del Movimiento de Trabajadores Desocupados de La Matanza. Buenos Aires: MTD Editora, 2007.

LUXEMBURGO, Rosa; LÊNIN, V.I. Partido de massas ou partido de vanguarda: polêmica Rosa/Lênin. São Paulo: Nova Stella Editorial, 1985.

MAZZEO, Miguel. E1 sueño de uma cosa: introducción al poder popular. Buenos Aires: editorial El Coletivo, 2007.

MONTERO, Maritza. Hacer para transformar: el método en la psicologia comunitaria. Buenos Aires: Paidós, 2006.

PETRAS, James. El menemismo: el contexto internacional de la década de 90. Revista Herramienta Revista de debate y crítica marxista, n. 12, 2000.

SVAMPA, Maristela e PEREYRA, Sebastián. Entre la ruta y el barrio: la experiencia de las organizaciones piqueteros. Buenos Aires: Biblos, 2003. 
TRAGTENBERG. Maurício. Uma prática de participação: as coletivizações na Espanha (1936/1939).

In: VENOSA, Roberto. Participação e participações:

ensaios sobre autogestão. São Paulo: Babel Cultural, 1987. p. 21-60.

ZIBECHI, Raul. Genealogia de la revuelta - Argentina: la sociedad en movimiento. La Plata: Letra Libre, 2003. 